\title{
Sensitivity, Internal Consistency and Factorial Structure of the Arabic Version of OMSAT-3
}

\author{
Guelmami Noômen"1, Jabri Mohamed1*, Houssem Nasri', Agrebi Brahim² \\ ${ }^{1}$ Research Unit, Sportive Performance and Physical Rehabilitation, High Institute of Sports and Physical \\ Education, Kef, University of Jendouba, Jendouba, Tunisia \\ ${ }^{2}$ High Institute of Sports and Physical Education, Ksar Said Tunis, University of Manouba, Manouba, Tunisia \\ Email: shandoman@yahoo.fr
}

Received 14 January 2015; accepted 2 February 2015; published 3 February 2015

Copyright (C) 2015 by authors and Scientific Research Publishing Inc.

This work is licensed under the Creative Commons Attribution International License (CC BY). http://creativecommons.org/licenses/by/4.0/

(c) (i) Open Access

\section{Abstract}

The aim of this study was to assess the sensitivity, internal consistency and the factorial structure of an Arabic version of OMSAT-3 among Tunisian athletes. A translated version of OMSAT-3 was administrated to a total of 526 Tunisian athletes from both sexes divided on elite $(n=240)$ and non-elite $(n=286)$ and aged between 16 and 19 years. The results showed robust psychometric properties for the Arabic version of the instrument: it was sensitive according to the level of practice (8/12 subscales could discriminate the elites and non-elites athletes). Cronbach's alpha revealed a good internal consistency ( $\alpha>0.70$ for all the subscales). Also, confirmatory factor analysis provides a good adjustment index and adequate factorial structure. This version in Arabic language presents acceptable psychometric proprieties to evaluate the mental skills of the athletes in Tunisia and in other Arabic countries.

\section{Keywords}

Sensitivity, Internal Consistency, Cross Cultural Validity, Factorial Analysis

\section{Introduction}

Throughout the two last decades, most empirical research in sport psychology has focused on the understanding and the formation of psychological skills (Gould et al., 2002; Vealey, 1994; McCaffrey \& Orlick, 1989; Mahoney et al., 1987). In this perspective, a variety of psychological inventories and questionnaires have been vali-

*Corresponding author.

How to cite this paper: Noômen, G., Mohamed, J., Nasri, H., \& Brahim, A. (2015). Sensitivity, Internal Consistency and Factorial Structure of the Arabic Version of OMSAT-3. Advances in Physical Education, 5, 18-25.

http://dx.doi.org/10.4236/ape.2015.51003 
dated and published. These instruments are able to evaluate specific skills in a multidimensional framework.

For a long time, the problem was how to question the overall usefulness and applicability of these tools in one specific psychological skill or ability (Chartrand, Jowdy, \& Danish, 1992). Related literature usually confirmed the need for assessment tools which allowed measuring a wide range of skills rather than separate components. With that in mind, early trials had attempted to develop and validate tools for multidimensional measure of psychological skills.

During many years, OMSAT (Ottawa Mental Skills Assessment Tool) was adjusted, rectified and developed assessing a range of mental skills used in the sport realm in order to distinguish and measure different psychological skills used to improve performances (Durand-Bush et al., 2001). This instrument development was a process. The original version of the Ottawa Mental Skills Assessment Tool (OMSAT) contained in its initial phase 14 skills grouped in five categories: basic skills (goal setting, commitment and belief), emotional competences (stress reaction, fear control, relaxation and energy), cognitive skills (mental imagery, mental practice, focusing and refocusing); competition skills (simulation and competition planning), and last team dynamics competences (Bota, 1993).

Bota (1993) submitted the OMSAT to statistical analysis to determine its reliability and validity. Acceptable results were found. However, its analysis has revealed that it would be more useful to have a shorter version of the questionnaire. This led to the development of the second version (OMSAT-2). In this revision, the mental skills were reduced to 12 skills and 71 items. Thus, the scale of the team dynamics was abandoned and the magnitude of the simulation was combined with the scale of the mental practice. A statistical analysis conducted by Draper, Salmela, \& Durand-Bush (1995) was used to check the psychometric properties of this version. Later, as the results of the examination of the OMSAT-2, an attempt to improve was led by Durand-Bush (1995) who provided an improved version (OMSAT-3). The psychometric proprieties confirmatory factorial analysis revealed that the model required a suitable adjustment, which led to the development of a more robust version of OMSAT-3. Confirmatory analysis in the second version, which included 48 items and 12 scales of mental skills grouped under three broader conceptual components basic, psychosomatic and cognitive skills, indicated that the proposed model corresponded to the empirical data. Thus, the OMSAT- 3 was able to discriminate between elite athletes and competitive level athletes in the majority of subscales. The results also showed temporal stability and acceptable internal consistency for the questionnaire. In the end, the OMSAT-3 seems to be a valid and reliable instrument to assess the entire population, that is to say, elites/non-elites, women/men and individual sport/team sport.

In this regard, we try to examine the psychometric properties of an Arabic translated version of OMSAT-3 with Tunisian athletes. Thus, we tested the sensitivity of the instrument and its internal consistency and we examined its factorial structure.

\section{Methodology}

\subsection{Participants}

A total of 526 competitive Tunisian athletes were recruited for the present study. These athletes were 105 soccer players (62 men and 43 women), 82 basketball players (44 men and 38 women), 78 volleyball players (42 men and 36 women), 65 handball players (38 men and 27 women); 102 athletes (59 men and 43 women) and 94 Martial art sports athletes (48 men and 46 women). The participants were divided into elite $(n=240)$ and nonelite $(n=286)$ athletes according to their level of performance.

Chronological ages of the participants were ranged between 12 and 19 years old.

\subsection{Measurement}

The third version of Ottawa Mental Skills Assessment Tool (OMSAT-3) developed by Durand-Bush et al. (2001) was translated into Arabic language then used to collect the psychometric data. This tool evaluates 12 mental skills, classified in 3 categories:

1) Basic skills (goals setting, self confidence and commitment);

2) Psychosomatic skills (stress reactions, fear control, relaxation and activation);

3) Cognitive skills (concentration, control of the distractions, imagery, mental practice and planning of the competitions). 
The scores are obtained on 7 points Likert scale. The psychometric properties of this scale showed robustness of measurement for the original version and the Romaine version (Craciun et al., 2008).

\subsection{Procedures}

The OMSAT-3 translation committee included a professional translator, linguistics' scientist and three specialists in psychology. A procedure of reverse translation was treated to see the robustness of the adapted version as described by Hambleton (1993).

The answers were collected over a period of three weeks after a written agreement from the directors and the coaches of the clubs.

\subsection{Statistical Analysis}

Sensitivity, internal consistency and factorial structure of the Arabic version of OMSAT-3 were explored.

The sensitivity was checked by multivariate and univariate analysis of variance tests.

Internal consistency is checked by Cronbakh's alpha. Tabachnick \& Fidell (2007) suggested a value of 0.70 of this coefficient for an acceptable internal consistency.

The factorial structure of the scale was demonstrated by a confirmatory factorial analysis (CFA) on each subscale. We exposed 7 index resulting from the confirmatory model: the Chi Square $\left(\chi^{2}\right)$, the degrees of freedom (df), Bentler's Comparative FIT Index (CFI), the Goodness of FIT Index (GFI), Pclose Fit Index (PCFI), Tucker-Lewis Index (TLI), and the Root Mean Square of Error Approximation (RMSEA). Hu \& Bentler (1999), Bentler (1990) and Tanaka (1993) require an index of parsimony $\chi^{2} /$ DDL less than 2 or higher than 5 in order to accept the model. Furthermore, the values of CFI, GFI, PCFI and TLI were recommended close to 0.90 , while a value of RMSEA was recommended lower than 0.50 .

The statistical data management and computations of statistics were performed using SPSS version 20.0 (SPSS Inc., Chicago, IL, USA) and the confirmatory factor analysis was accomplished with SPSS Amos version 20.0 (SPSS Inc., Chicago, IL, USA).

The Multivariate normality of the data was provided by the Multivariate Kurtosis Mardia Coefficient.

\section{Results}

Table 1 shows the descriptive data statistics for elites and non elite athletes on OMSAT-3 subscales.

\subsection{Sensitivity}

Multivariate and univariate variance analysis were realized by the 12 OMSAT- 3 sub-scales. The results of Multivariate variance analysis revealed that $\mathrm{F}_{(12,513)}=1.88$ was significant $(p<0.05)$. The Univariate variance analysis showed that $8 / 12$ subscales could discriminate the elites athletes and non-elites athletes: goal setting $\left(\mathrm{F}_{(1,524)}\right.$ $=7.62 ; p<0.01)$, commitment $\left(\mathrm{F}_{(1,524)}=5.20 ; p<0.01\right)$, stress reaction $\left(\mathrm{F}_{(1,524)}=5.27 ; p<0.05\right)$; imagery $\left(\mathrm{F}_{(1}\right.$, $\left.{ }_{524)}=6.87 ; p<0.01\right)$, mental practical $\left(\mathrm{F}_{(1,524)}=4.63 ; p<0.05\right)$; control distractions $\left(\mathrm{F}_{(1,524)}=5.26 ; p<0.05\right)$; planning of the competitions $\left(\mathrm{F}_{(1,524)}=10.85 ; p<0.01\right)$.

\subsection{Internal Consistency}

Coronbach's alpha coefficients of OMSAT-3 subscales are all above 0.70: goal setting (alpha $=0.85$ ); self confidence $($ alpha $=0.86)$; commitment $($ alpha $=0.86)$; stress reaction $($ alpha $=0.85)$; fear control $($ alpha $=0.81)$; Relaxation (alpha $=0.85)$; activation (alpha $=0.82)$; imagery (alpha $=0.77)$; mental practical (alpha $=0.81)$; Focusing $($ alpha $=0.77)$; refocusing $($ alpha $=0.79)$; and competition planning $($ alpha $=0.81)$.

\subsection{Confirmatory Analysis of OMSAT-3}

We carried out confirmatory factorial analysis (CFA) of the first and second order using the robust method of Maximum Likelihood estimate.

The results of the indexes resulting from the CFA reveal suitable conformity factorial structure with the ideal model (see Table 2).

The robustness of an item is better as much as its Factor loadings are high. Comrey \& Lee (1992) suggested 
Table 1. Descriptive statistics of OMSAT-3 scales for elites $(n=240)$ and non-elites $(n=286)$.

\begin{tabular}{|c|c|c|c|}
\hline OMSAT-3 subscales & Level of practice & Means & Standard deviation \\
\hline \multirow{2}{*}{ Goal setting (GS) } & Elite & 4.75 & 1.43 \\
\hline & Non-elites & 4.4 & 1.47 \\
\hline \multirow{2}{*}{ Self confidence (SC) } & Elite & 4.81 & 1.53 \\
\hline & Non-elites & 4.55 & 1.57 \\
\hline \multirow{2}{*}{ Commitment (CO) } & Elite & 5.06 & 1.5 \\
\hline & Non-elites & 4.76 & 1.43 \\
\hline \multirow{2}{*}{ Stress reactions (SR) } & Elite & 4.76 & 1.57 \\
\hline & Non-elites & 4.46 & 1.42 \\
\hline \multirow{2}{*}{ Fear control (FC) } & Elite & 4.86 & 1.4 \\
\hline & Non-elites & 4.45 & 1.4 \\
\hline \multirow{2}{*}{ Activation (AC) } & Elite & 4.61 & 1.4 \\
\hline & Non-Elites & 4.4 & 1.32 \\
\hline \multirow{2}{*}{ Relaxation (RLX) } & Elite & 4.65 & 1.49 \\
\hline & Non-elites & 4.52 & 1.36 \\
\hline \multirow{2}{*}{ Imagery (IMG) } & Elite & 4.75 & 1.34 \\
\hline & Non-elites & 4.46 & 1.2 \\
\hline \multirow{2}{*}{ Mental practice (MP) } & Elite & 4.66 & 1.37 \\
\hline & Non-elites & 4.41 & 1.3 \\
\hline \multirow{2}{*}{ Focusing (FOC) } & Elite & 4.68 & 1.36 \\
\hline & Non-elites & 4.46 & 1.3 \\
\hline \multirow{2}{*}{ Refocusing (RFOC) } & Elite & 4.54 & 1.43 \\
\hline & Non-elites & 4.27 & 1.31 \\
\hline \multirow{2}{*}{ Competition planning $(\mathrm{CP})$} & Elite & 4.89 & 1.3 \\
\hline & Non-elites & 4.52 & 1.21 \\
\hline
\end{tabular}

Table 2. The first and second order adjustment of CFA of OMSAT-3.

\begin{tabular}{rcccccccc}
\hline & $\chi^{2}$ & DDL & $\chi^{2} /$ DDL & GFI & TLI & CFI & PCFI & RMSEA \\
\hline First order CFA & 1412 & 1014 & 1.39 & 0.90 & 0.96 & 0.96 & 0.86 & 0.027 \\
Second order CFA & 1514.60 & 1065 & 1.42 & 0.89 & 0.95 & 0.96 & 0.90 & 0.028 \\
\hline
\end{tabular}

that a factorial weight higher than 0.71 is considered as excellent, higher than 0.63 is rated as very good, higher than 0.55 is acceptable and inferior to 0.45 is considered poor.

In the present study, the first order confirmatory factorial analysis of the 48 items of OMSAT- 3 showed excellent factorial weights for 34 items, good factorial weights of 15 items and only one item has an acceptable factorial weight (the imagery sub-scale) (see Figure 1).

The psychometric data always has non-normal multivariate distribution. Thus we tested the multivariate normality of the data by the Mardia coefficient. The results demonstrated non-normal distribution for both elites and non-elites (Multivariate Kurtosis $=179.36$; $\mathrm{z}=6.15, p<0.001$ ). 

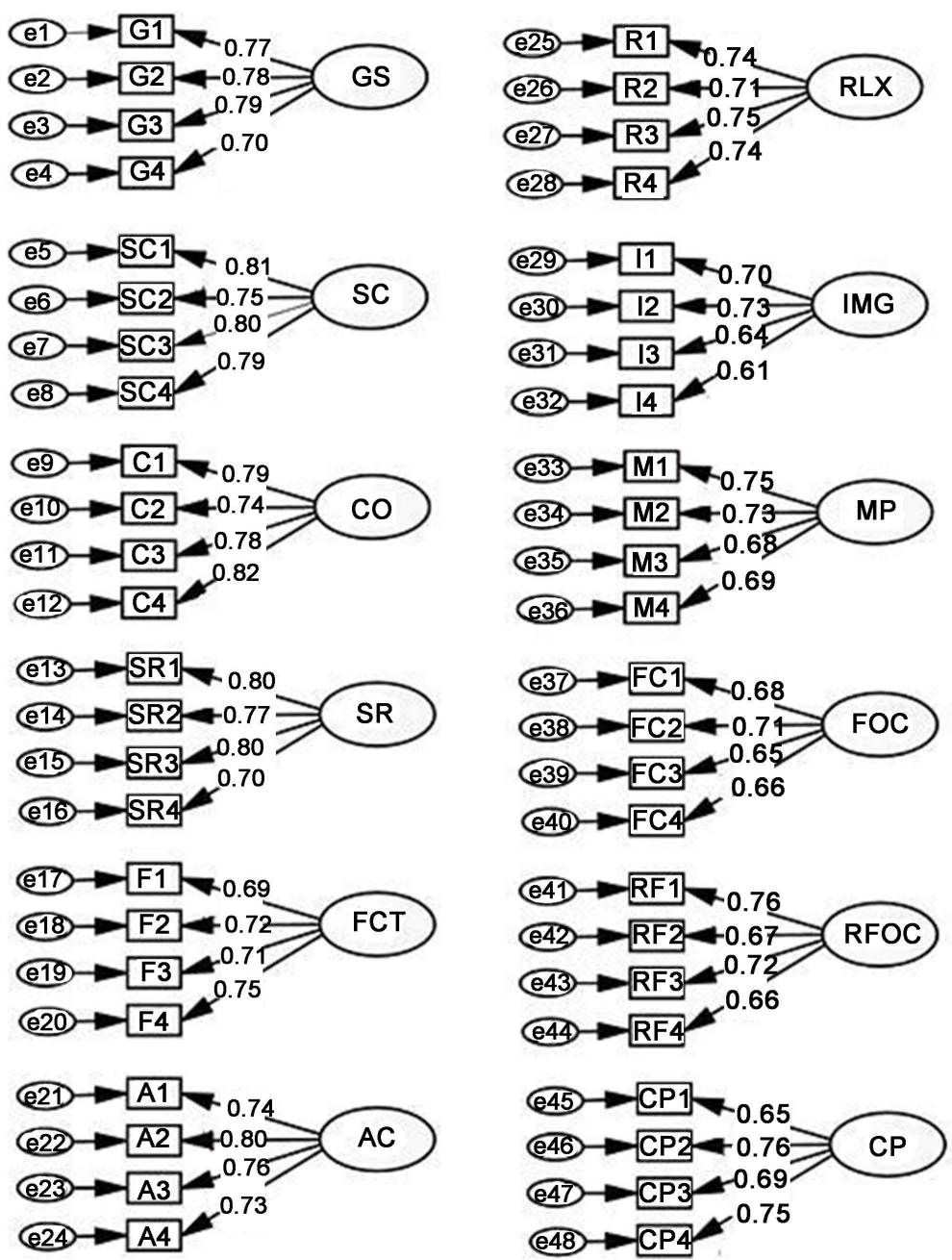

Figure 1. First order confirmatory factor analysis of the OMSAT-3 Arabic version. All parameters are significant at the 0.05 level (G1 to CP4: 48 items of OMSAT-3; e1 to e48: items errors).

The second order CFA aimed to test the ideal model elaborated from the initial version ranging the OMSAT-3 subscales in 3 categories: 1) basic skills (goal setting, self confidence and commitment); 2) psychosomatic skills (stress reaction, fear control, relaxation and activation); 3) cognitive skills (imagery, mental practice, focusing, refocusing and competition planning).

In accordance with the original version's confirmatory analysis where all hypothesized relationships were significant and of acceptable magnitude, the results of second order CFA shows that the factorial weights of the loading factors and adjustment indexes are adequate to represent the model (see Table 1 and Figure 2) (DurandBush et al., 2001).

The correlation between the scale's components was carried out to examine whether it has excessive multicolinearity between the factors. The Pearson correlation table indicates that all correlation coefficients are lower than 0.70 (see Table 3).

\section{Discussion}

The aims of the present study were 1) to show the sensitivity and the internal consistency of the Arabic version of OMSAT-3 for elites and non elites athletes, and 2) to examine the factorial structure of Arabic translated version of the OMSAT-3 as a robust tool to evaluate mental skills in sport context. The results showed robust assessments in term of sensitivity and internal consistency similar to original instrument and cross-cultural de- 


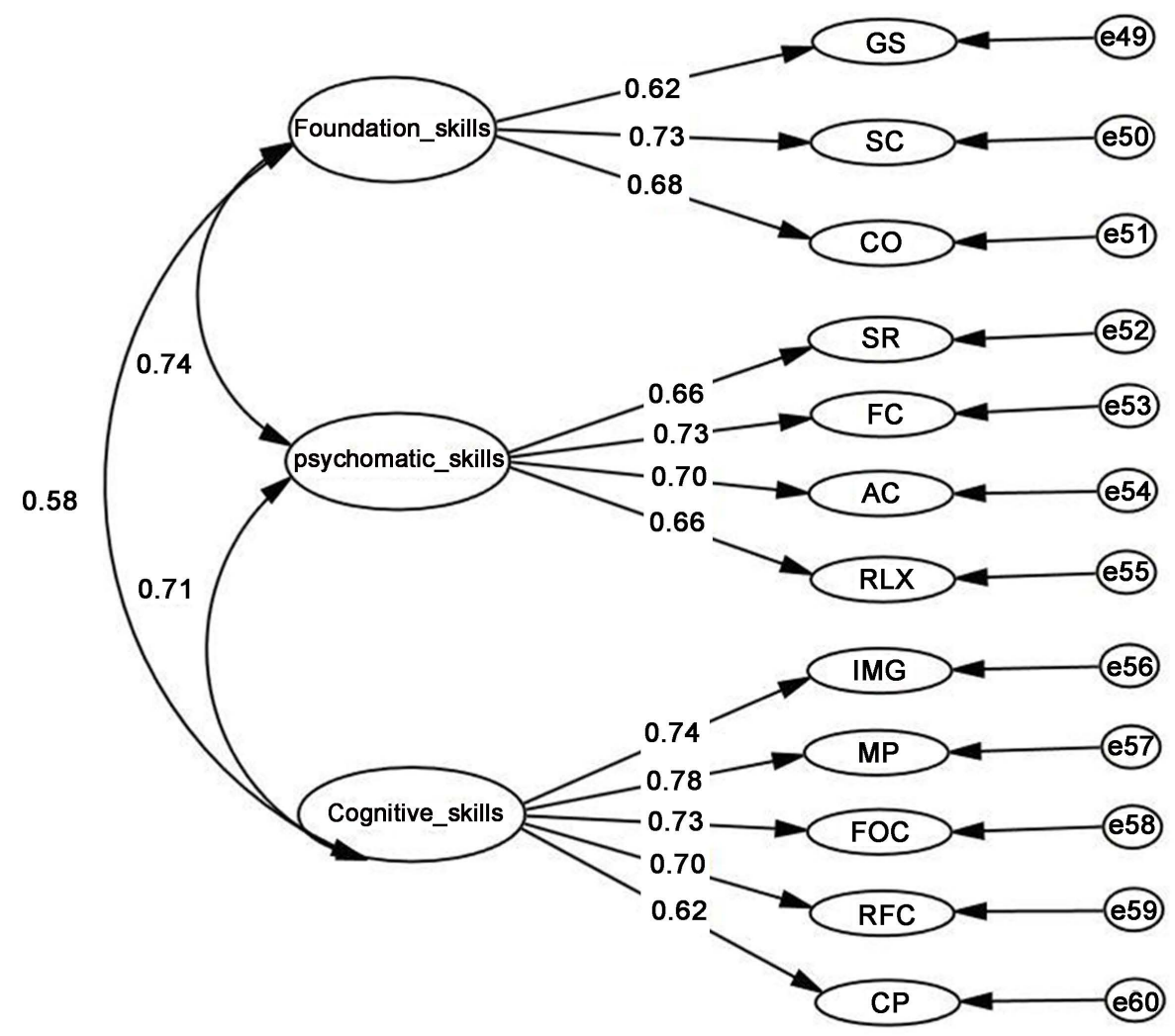

Figure 2. Second order confirmatory analysis of the OMSAT-3 Arabic version. All parameters are significant at the 0.05 level.

Table 3. Correlations Matrix of the OMSAT-3 12 scales.

\begin{tabular}{|c|c|c|c|c|c|c|c|c|c|c|c|c|}
\hline & 1 & 2 & 3 & 4 & 5 & 6 & 7 & 8 & 9 & 10 & 11 & 12 \\
\hline \multicolumn{13}{|l|}{ 1-GS } \\
\hline 2-SC & $0.390^{* *}$ & & & & & & & & & & & \\
\hline 3-CO & $0.340^{* *}$ & $0.446^{* *}$ & & & & & & & & & & \\
\hline 4-SR & $0.301^{* *}$ & $0.247^{* *}$ & $0.309^{* *}$ & & & & & & & & & \\
\hline 5-FC & $0.312^{* *}$ & $0.307^{* *}$ & $0.319^{* *}$ & $0.393^{* *}$ & & & & & & & & \\
\hline 6-AC & $0.245^{* *}$ & $0.371^{* *}$ & $0.327^{* *}$ & $0.374^{* *}$ & $0.403^{* *}$ & & & & & & & \\
\hline 7-RLX & $0.230^{* *}$ & $0.237^{* *}$ & $0.236^{* *}$ & $0.396^{* *}$ & $0.368^{* *}$ & $0.357^{* *}$ & & & & & & \\
\hline 8-IMG & $0.291^{* *}$ & $0.297^{* *}$ & $0.282^{* *}$ & $0.296^{* *}$ & $0.330^{* *}$ & $0.291^{* *}$ & $0.361^{* *}$ & & & & & \\
\hline 9-MP & $0.225^{* *}$ & $0.257^{* *}$ & $0.228^{* *}$ & $0.279^{* *}$ & $0.332^{* *}$ & $0.351^{* *}$ & $0.363^{* *}$ & $0.520^{* *}$ & & & & \\
\hline 10-FOC & $0.268^{* *}$ & $0.224^{* *}$ & $0.187^{* *}$ & $0.252^{* *}$ & $0.241^{* *}$ & $0.267^{* *}$ & $0.273^{* *}$ & $0.333^{* *}$ & $0.414^{* *}$ & & & \\
\hline 11-REF & $0.251^{* *}$ & $0.199^{* *}$ & $0.148^{* *}$ & $0.231^{* *}$ & $0.239^{* *}$ & $0.237^{* *}$ & $0.293^{* *}$ & $0.382^{* *}$ & $0.402^{* *}$ & $0.504^{* *}$ & & \\
\hline 12-CP & $0.177^{* *}$ & $0.261^{* *}$ & $0.162^{* *}$ & $0.283^{* *}$ & $0.247^{* *}$ & $0.245^{* *}$ & $0.274^{* *}$ & $0.327^{* *}$ & $0.326^{* *}$ & $0.396^{* *}$ & $0.373^{* *}$ & \\
\hline
\end{tabular}

${ }^{* *}$ The correlation is significant for $p=0.01$.

veloped tools. In addition, the first and second factor CFA revealed that the factorial structure established in Arabic language confirmed the latent model of the postulated theory.

The comparison between elite and non elite athletes was on line with various empirical studies trying to cha- 
racterize the elite athletes' mental skills (Macnamara, 2013; Ghasemi, 2012). Initial work of McCaffery \& Orlich (1989) and Mahonney et al. (1987) identified the mental skills leading to excellence in sport performance. Kendall et al. (1990) could highlight the effect of the mental training on the sport performance. In the two last decades, much of empirical research identified that mental skills are able to discriminate between the elite and the non-elite athletes in several sports disciplines. Similarly, Williams \& Krane (2001) examined specific bibliography and could identify some psychological characteristics to justify the Olympic success: they quote high confidence, self talk, commitment, goal setting and the control strategies. One year later, Gould et al. (2002) identified commitment, the goal setting and the motivation as useful factors to discriminate the elites from the other athletes.

Other studies (for example: Durand-Bush et al., 2001, Gould et al., 1993a; 1993b) revealed that elite athletes use mental technical method like relaxation. Calmels et al. (2003) and Cumming \& Hall (2002) demonstrated that elite athletes use much more the mental imagery techniques. Recent studies such as the work of Pashabadi et al. (2011), Salmela et al. (2009), Andrew et al. (2007) and Demuth et al. (2007) showed that mental skills such as motivation, stress reaction, fear control, self-confidence, relaxation, and mental effectiveness frame characterized the elite's athletes.

The results of the previous works concerning the mental skills are always linked to the social and cultural environment of the athletes.

The indexes of adjustment resulting from the CFA in the first and the second order confirmed that the Arabic version of OMSAT-3 were adequate, robust and able to represent the initial model created by Durand-Bush et al. (2001) where the 12 scales model represented relevantly the covariance within the sample. Our version seems to represent the covariance within the sample in a more satisfactory manner than the original version. Moreover, the three broader conceptual components proposed in the original version are perfectly reproduced in our Arabic version.

In this research we were incapable to validate the questionnaire on a larger population with the same ages as the original version. Also, it would be very useful to explore the mental skills deeper especially to find solutions and explanations to precocious talent abundant phenomenon. Low levels of mental skills predisposition are presented as the main causes.

\section{Conclusion}

This aim of this study is to evaluate the psychometric properties of a translated Arabic version of OMSAT-3 among Tunisian athletes. Good psychometric properties of this version of OMSAT-3 were shown in the present research. The factorial structure showed acceptable model of the instrument. The development of this version gives the possibility for the psychologists and the coaches in the Arabic countries to use this preliminary translation to explore the mental skills of their athletes. Nevertheless, other empirical work and varied samples are necessary to approve definitively this version.

\section{References}

Andrew, M., Grobbelaar, H. W., \& Potgieter, J. C. (2007). Sport Psychological Skill Levels and Related Psychosocial Factors That Distinguish between Rugby Union Players of Different Participation Levels. Physical Education and Recreation, 29, 1-14.

Bentler, P. M. (1990). Comparative Fit Indexes in Structural Models. Psychological Bulletin, 107, 238-246.

Bota, J. D. (1993). Development of the Ottawa Mental Skills Assessment Tool (OMSAT). Master's Thesis, Ottawa: University of Ottawa.

Calmels, C., d'Arripe-Longueville, F., Fournier, J. F., \& Soulard, A. (2003). Competitive Strategies among Elite Female Gymnasts: An Exploration of the Relative Influence of Psychological Skills Training and Natural Learning Experiences. International Journal of Sport and Exercise Psychology, 1, 327-352. http://dx.doi.org/10.1080/1612197X.2003.9671724

Chartrand, J. M., Jowdy, D. P., \& Danish, S. J. (1992). The Psychological Skills Inventory for Sports: Psychometric Characteristics and Applied Implications. Journal of Sport \& Exercise Psychology, 14, 405-413.

Comrey, A. L., \& Lee, H. B. (1992). A First Course in Factor Analysis (2nd ed.). Hillsdale, NJ: Lawrence Erlbaum.

Craciun, M., Dobosi, S., Loan, N., \& Prodea, C. (2008). Confirmatory Factor Analysis of the Ottawa Mental Skill Assessment Tool (OMSAT-3*)-Romanian Version. Human Movement, 12, 159-164.

Cumming, J., \& Hall, C. (2002). Deliberate Imagery Practice: The Development of Imagery Skills in Competitive Athletes. Journal of Sports Sciences, 20, 137-145. http://dx.doi.org/10.1080/026404102317200846 
Demuth, A., Czerniak, U., Krzykata, M., Wielinski, D., \& Ziótkowska-lajp, E. (2007). Somatic Characteristic of Players Form Chosen National Teams of Field Hockey. Human Movement, 8, 21-31.

Draper, S. P., Salmela, J. H., \& Durand-Bush, N. (1995). The Ottawa Mental Skills Assessment Tool: A Confirmatory Factor Analysis. Paper Presented at La fédération européenne de la psychologie du sport et de l'activité corporelle, Bruxelles.

Durand-Bush, N. (1995). Validity and Reliability of the Ottawa Mental Skills Assessment Tool (OMSAT-3). Master's Thesis, Ottawa: University of Ottawa.

Durand-Bush, N., Salmela, J. H., \& Green-Demers, I. (2001). The Ottawa Mental Skills Assessment Tool (OMSAT-3). The Sport Psychologist, 15, 1-19.

Ghasemi, A., Yaghoubian, A., \& Momeni, M. (2012). Mental Toughness and Success Levels among Elite Fencers. Advances in Environmental Biology, 6, 2536-2540.

Gould, D., Dieffenbach, K., \& Moffett, A. (2002). Psychological Characteristics and Their Development in Olympic Champions. Journal of Applied Sport Psychology, 14, 172-204. http://dx.doi.org/10.1080/10413200290103482

Gould, D., Finch, L. M., \& Jackson, S. A. (1993a). Coping Strategies Used by National Champion Figure Skaters. Research Quarterly for Exercise and Sport, 64, 453-468. http://dx.doi.org/10.1080/02701367.1993.10607599

Gould, D., Jackson, S., \& Finch, L. (1993b). Sources of Stress in the US National Champion Figure Skaters. Journal of Sport and Exercise Psychology, 15, 134-159.

Hambleton, R. K. (1993). Translating Achievement Tests for Use in Cross-National Studies. European Journal of Psychological Assessment, 9, 57-68.

Hu, L. T., \& Bentler, P. M. (1999). Cutoff Criteria for Fit Indexes in Covariance Structure Analysis: Conventional Criteria versus New Alternatives. Structural Equation Modeling: A Multidisciplinary Journal, 6, 1-55. http://dx.doi.org/10.1080/10705519909540118

Kendall, G., Hrycaiko, D., Martin, G. L., \& Kendall, T. (1990). The Effects of an Imagery Rehearsal, Relaxation, and SelfTalk Package on Basketball Game Performance. Journal of Sport \& Exercise Psychology, 12, 157-166.

Macnamara, A., \& Collins, D. (2013). Do Mental Skills Make Champions? Examining the Discriminant Function of the Psychological Characteristics of Developing Excellence Questionnaire. Journal of Sports Sciences, 31, 736-744. http://dx.doi.org/10.1080/02640414.2012.747692

Mahoney, M. J., Gabriel, T. J., \& Perkins, T. S. (1987). Psychological Skills and Exceptional Athletic Performance. Sport Psychologist, 1, 189-199.

McCaffrey, N., \& Orlick, T. (1989). Mental Factors Related to Excellence among Professional Golfers. International Journal of Sport Psychology, 20, 256-278.

Pashabadi, A., Shahbazi, M., Hoseini, S. M., Mokaberian, M., Kashanai, V., \& Heidari, A. (2011). The Comparison of Mental Skills in Elite and Sub-Elite Male and Female Volleyball Players. Procedia-Social and Behavioral Sciences, 30, 15381540. http://dx.doi.org/10.1016/j.sbspro.2011.10.298

Salmela, J. H., Monfared, S. S., Mosayebi, F., \& Durand-Bush, N. (2009). Mental Skill Profiles and Expertise Levels of Elite Iranian Athletes. International Journal of Sport Psychology, 40, 361-373.

Tabachnick, B. G., \& Fidell, L. S. (2007). Using Multivariate Statistics (5th ed.). New York: Harper Collins.

Williams, J. M., \& Krane, V. (2001). Psychological Characteristics of Peak Performance. In J. M. Williams (Ed.), Applied Sport Psychology: Personal Growth to Peak Performance (4th ed., pp. 137-147). Mountain View, CA: Mayfield. 
Scientific Research Publishing (SCIRP) is one of the largest Open Access journal publishers. It is currently publishing more than 200 open access, online, peer-reviewed journals covering a wide range of academic disciplines. SCIRP serves the worldwide academic communities and contributes to the progress and application of science with its publication.

Other selected journals from SCIRP are listed as below. Submit your manuscript to us via either submit@scirp.org or Online Submission Portal.
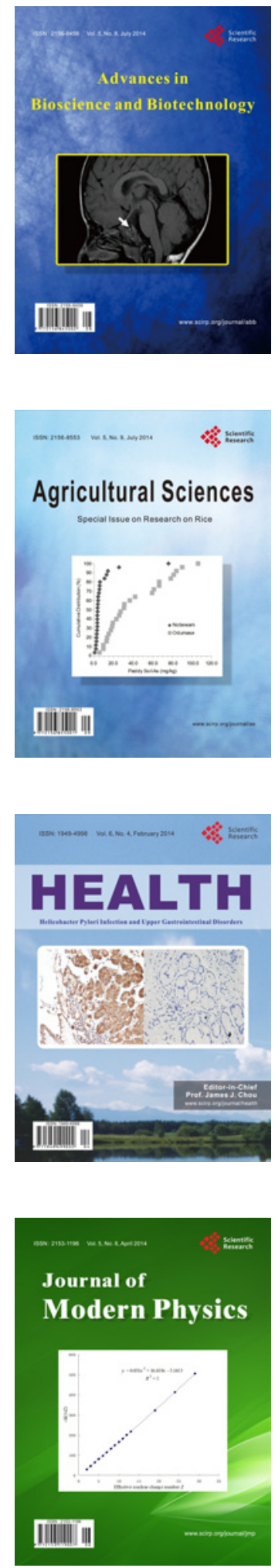
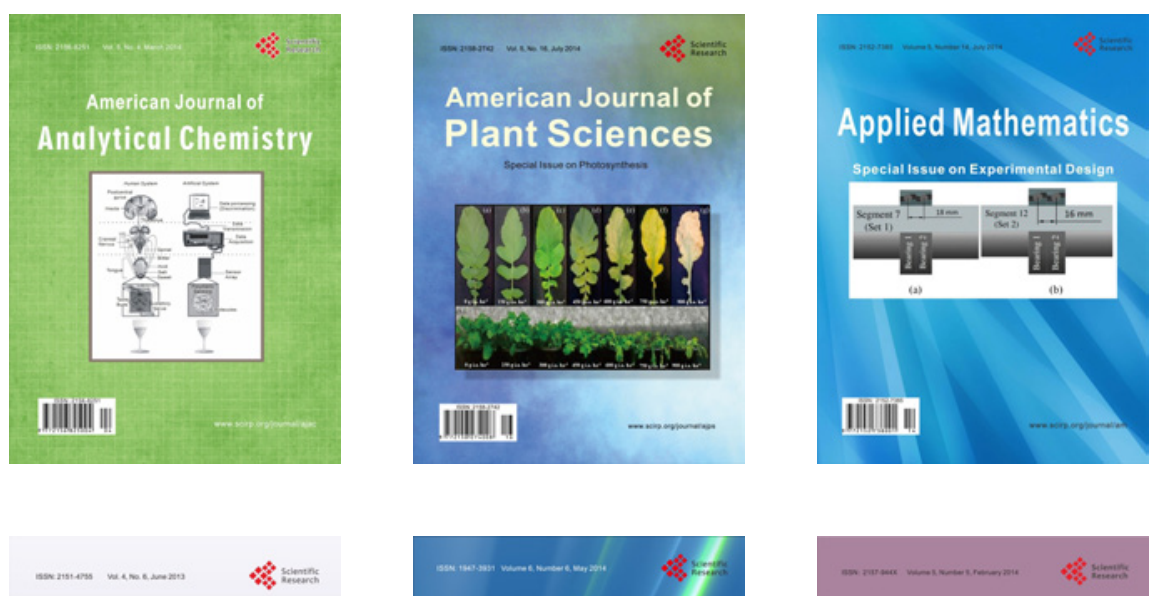

Creative Education
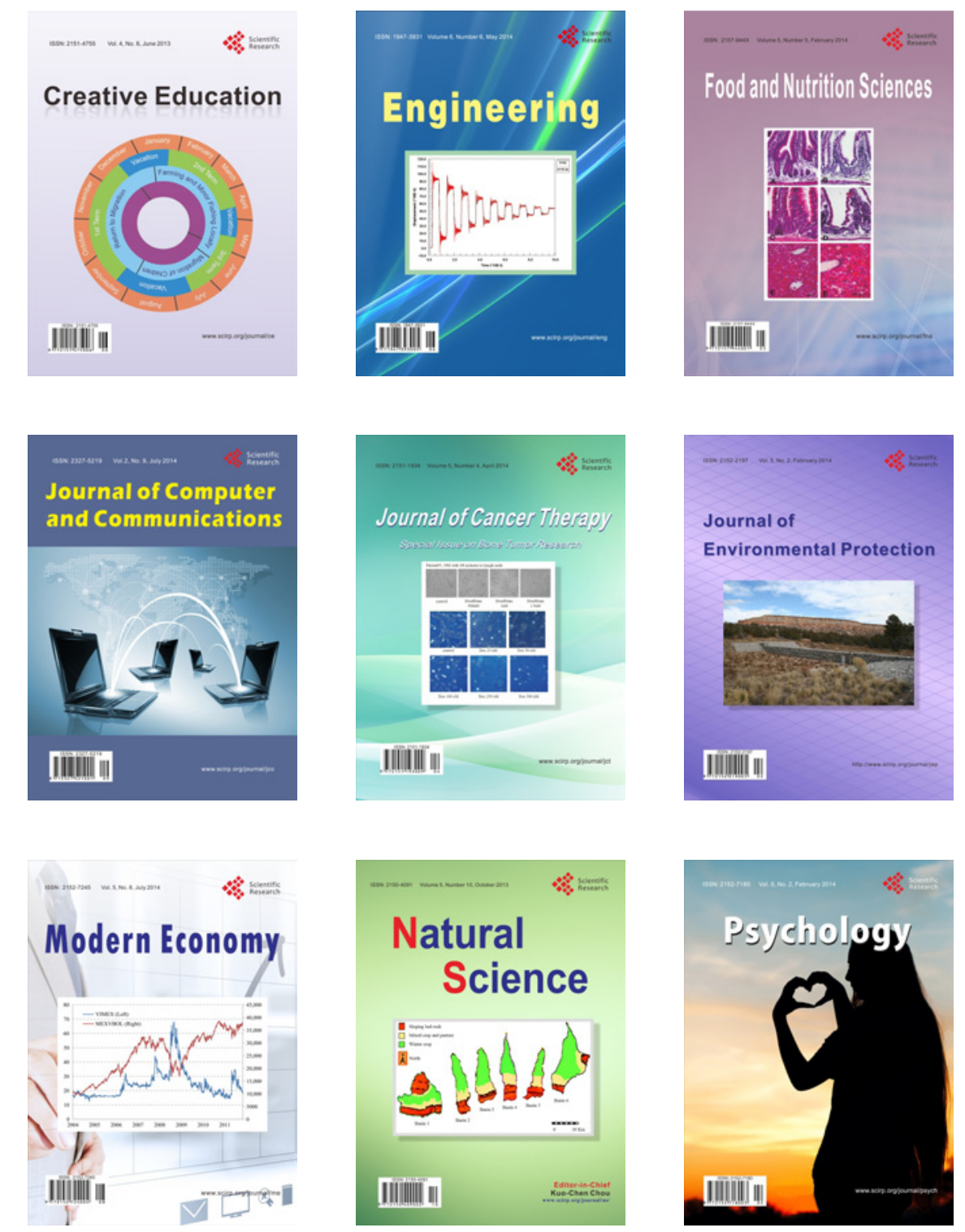